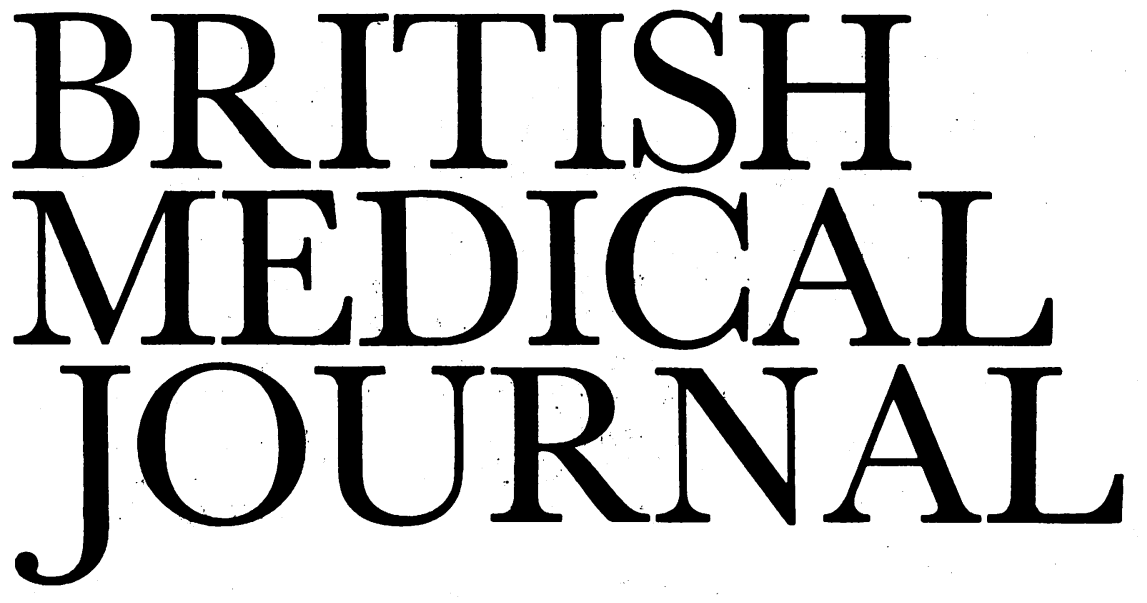

LONDON, SATURDAY 23 MAY 1987

\title{
Cervical smears: new terminology and new demands
}

A report on a cervical smear indicates a course of action. The message must therefore be clear - for any confusion may lead to the wrong or even a dangerous response. Confusion should not occur if all reports used a common, clearly defined vocabulary, but, regrettably, they do not. A plethora of classifications, terminologies, and numerical rubrics is used. Doctors moving from one area to another may encounter reports couched in totally different terms. To try to overcome these serious deficiencies the British Society for Clinical Cytology set up a working party to define and recommend terms for general use in cervical cytology. The working party has now produced a clear and sensible document which recommends that a cervical cytology report should consist of a concise description of the cells present in clearly defined and generally accepted terms, a prediction of the histological condition, and a recommendation for the further management of the patients. ${ }^{1}$

The working party recommends that nuclear abnormalities should form the basis of a cytological diagnosis. If nuclear abnormalities are absent then the smear result is "negative." Nuclear abnormalities when present range from those of minor degree, usually associated with inflammatory conditions, to more striking abnormalities associated with either cervical intraepithelial neoplasia or with invasive carcinoma. The term "dyskaryosis" is recommended to describe nuclear abnormalities greater than those encountered in inflammatory conditions, and dyskaryotic cells thus indicate a diagnosis of either cervical intraepithelial neoplasia or invasive carcinoma. The degree of dyskaryotic change probably correlates roughly with the severity of the histological lesion: mild dyskaryosis indicates cervical intraepithelial neoplasia grade 1 , moderate dyskaryosis cervical intraepithelial neoplasia grade 2, and severe dyskaryosis either cervical intraepithelial neoplasia grade 3 or invasive carcinoma. The cytologist cannot reliably diagnose an invasive carcinoma from a smear; he can, however, recognise several features that together suggest an invasive neoplasmand he should then say so in the report. In some smears the nuclear abnormalities will fall between those characteristic of inflammatory disease and those of dyskaryosis: the term "borderline" should be applied to such smears. In this classification emphasis is placed on the nuclear abnormalities; cytoplasmic changes may be taken into account but are not paramount. The terms "atypia" and "malignant," which often figure in other classifications, do not appear in the recommended terminology.

The recommendations of the working party merit universal adoption. The doctor receiving a report using the terms recommended by the working party should know what to do. Ideally, all women with dyskaryotic cells in their smears should be referred for colposcopy, irrespective of the degree of abnormality. Doctors know that immediate referral is the correct response to severely dyskaryotic cells, but until recently it has not been recognised that this is also true for women with smears showing mild or moderate dyskaryosis. Recent reports of histologically proved cervical intraepithelial neoplasia grade 3 being found in women whose smears showed only mild dyskaryosis ${ }^{23}$ are confirmed by two studies in this issue (p 1313 and p 1326). Thus the presence of only mildly dyskaryotic cells in a smear should be treated with the utmost seriousness, and the chilling consequences of failure to do so are graphically illustrated on p 1337. Cervical intraepithelial neoplasia has also been found in about one fifth of women with persistent inflammatory smears (p 1326) 4 and these women too require colposcopy.

The difficulty is that the referral of all women with mildly dyskaryotic or persistently inflammatory smears will place an unacceptable burden on a colposcopy service that is in many areas already stretched to its limits. The inevitable increase in referrals for colposcopy can be met only by considerably increasing the number of trained colposcopists. The imaginative setting up of colposcopy clinics in general practice ( $p$ 1326) and in a family planning clinic ( $p$ 1313) shows that colposcopy can be successfully performed outside hospitals, and the development of such clinics may be not only desirable but also vital. But irrespective of where colposcopy is performed the number of colposcopically directed biopsies will inevitably increase, which will place further strain on the histopathology services.

The unpalatable fact remains that in many districts the immediate referral for colposcopy of women with smears showing mild dyskaryosis will not be practicable. In these circumstances the women should have a repeat smear in three to six months, and if it shows any dyskaryosis, no matter how mild, the patient should be referred for colposcopy and biopsy. If the repeat smear shows no abnormality it should be repeated after one year. This course of action is, however, far from ideal: for the Glasgow study shows that nearly $12 \%$ of 
women whose repeat smears after finding mild dyskaryosis are negative have cervical intraepithelial neoplasia on biopsy. Compromise is inevitable with inadequate colposcopy services in Britain, but compromise may sometimes mean death.

Professor of Reproductive Pathology,

H Fox

University of Manchester,

Manchester M13 9PT

1 Evans DMD, Hudson EA, Brown CL, et al. Terminology in gynaecological cytopathology: report of the working party of the British Society for Clinical Pathology. $\mathcal{F}$ Clin Pathol 1986;39:933-44. 2 Soutter WP, Wisdom S, Brough AK, Monaghan JM. Should patients with mild atypia in a cervica smear be referred for colposcopy? Br $\mathcal{F}$ Obstet Gynaecol 1986;93:70-4

Walker EM, Dodgson J, Duncan ID. Does mild atypia warrant further investigation? Lance 1986;ii:672-3.

4 Singer A. The abnormal cervical smear. Br Med f 1986;293:1551-6.

\section{Should sympathomimetics be available over the counter?}

The abuse of amphetamine and the resultant paranoid psychoses are well recognised, ${ }^{1}$ and similar problems may arise from the abuse of other sympathomimetics such as methylphenidate, diethylpropion, and phenmetrazine. ${ }^{2}$ Not surprisingly these drugs came to be made available only on prescription and were subsequently classed as controlled drugs. Nevertheless, sympathomimetic drugs such as ephedrine, pseudoephedrine, and phenylpropanolamine, which have similar propensities, remain available over the counter. ${ }^{3.5}$ They are common constituents in cough and cold remedies, which are by far the largest category of nonprescription sales in Britain, ${ }^{6}$ and which in overdose may be fatal.

In the United States the abuse of over the counter sympathomimetics has become recognised as a national problem, ${ }^{8-10}$ with terms such as pseudospeed, look alikes, and pea shooters. Pseudospeed is a generic term given to various combinations of non-prescription stimulants such as ephedrine, phenylpropanolamine, and caffeine.$^{10}$ Look alikes are the same stimulants packaged closely to resemble amphetamine tablets in size, colour, numbering, and trademark, enabling them to be sold on the street as such. Look alikes are said to have first appeared in the south eastern United States, where they were sold as amphetamines. ${ }^{9}$ During the 1970 s phenylpropanolamine was used increasingly as an over the counter appetite suppressant and was eventually incorporated into look alike drugs. ${ }^{8}$ By 1980 most look alikes contained ephedrine, phenylpropanolamine, and caffeine. They were manufactured in "garage laboratories" and sold cheaply by mail order. ${ }^{10}$ Four such look alike capsules might be as potent as a substantial dose of amphetamine. ${ }^{9}$

Congressional hearings held in 1981 and 1983 considered the pseudospeed problem but the Food and Drug Administration was unable to stop manufacture as these were over the counter drugs. They were, however, able to prevent counterfeiting controlled drugs and to seize look alikes. The look alike industry responded by changing the appearance of its products. The United States Postal Service then refused to deliver phenylpropanolamine, ephedrine, and caffeine on the grounds that the triple combination was not safe as advertised. In August 1983 the Food and Drug Administration banned its sale but the look alike industry removed one of the constituents, whereupon in December 1983 the Food and Drug Administration banned the combination of phenylpropanolamine and caffeine. Currently, legally produced pseudospeed contains only one sympathomimetic and is usually sold as an over the counter appetite suppressant. ${ }^{9}$ The growing popularity of cocaine in the United States and its high price have also resulted in pseudospeed being marketed as a substitute for cocaine with names such as "cokesnuff," "coca snow incense," and "poor man's cocaine." 112 Pseudospeed has been reported as the most commonly abused drug after alcohol and cannabis among adolescents in central New York. ${ }^{10}$ The pseudospeed industry has a multimillion dollar turnover, makes vast profits, and has always been one step ahead of any legislation designed to curb the drug.

Abuse of over the counter sympathomimetics is a major problem in the United States, and, like solvent abuse, it might cross the Atlantic. There is a strong case for making them available here only on prescription; this may help to prevent the development of abuse in the United Kingdom.

ANDREW WHITEHOUSE

Clinical Lecturer,

University Department of Psychiatry,

Addenbrooke's Hospital,

Cambridge CB2 2QQ

1 Connell PH. Amphetamine psychosis, London: Oxford University Press, 1958. (Maudsley Monographs No 5 .)

2 Ellinwood EH, Rockwell WJK. Central nervous systems stimulants and anorectic drugs. In: Dukes MHG, ed. Meyler's side effects of drugs. Vol X. Amsterdam: Elsevier, 1984:1-23.

3 Whitehouse AM, Duncan JM. Ephedrine psychosis rediscovered. Br $\mathcal{f}$ Psychiatry 1987, 150:258-61.

4 Leighton KM. Paranoid psychosis after abuse of Actifed. Br Med f 1982;284:789-90.

5 Wharton BK. Nasal decongestants and paranoid psychosis. Br f Psychiatry 1970;117:439-40.

6 Anonymous. Cough medicines (Editorial). Drug Ther Bull 1985;22:85-7.

7 Logie AW, Scott CM. Fatal overdose of phenylpropanolamine. Br Med f 1984;289:591.

8 Lake CR, Algana SW, Moriarty K, Quirk RS, Gamble E, Reid A. Use and abuse of look-alike stimulant drugs. Medical foumal of the United States Army 1985;42:16-20.

Lake CR, Quirk RD. CNS stimulants and the look-alike drugs. Psychiatr Clin North Am 1984;7:689-701.

10 Dougherty RJ. Pseudo-speed, look-alikes or pea-shooters. NY State 7 Med 1982;1:74-5.

11 Seigel RK. Cocaine substitutes. N Engl F Med 1982;302:817.

12 Mack RB. Are your patients speeding? NC Med f 1981;42:489.

\section{Special units for acute upper gastrointestinal bleeding}

The management of patients with acute upper gastrointestinal bleeding remains controversial, partly because of different and sometimes conflicting medical interests. Endoscopists have reported that endoscopy is better than radiology, ${ }^{1}$ radiologists that radiology is better than endoscopy, ${ }^{2}$ surgeons that an early operation reduces mortality, and physicians that an early operation increases mortality. We must therefore look closely at a claim from an Australian hospital that setting up a special multidisciplinary unit reduced mortality from acute upper gastrointestinal bleeding from $15 \%$ to $6 \%$ in a few years. ${ }^{5}$

Mortality in patients admitted to hospital with acute upper gastrointestinal bleeding has remained fairly constant at around $10 \%$ over the past 40 years, although the proportion of elderly patients has increased enormously. ${ }^{6}$ As many as two thirds of patients are now over 60 , and a quarter over $80 .^{7}$ Deaths are virtually confined to these elderly patients, ${ }^{8}$ and the death rate is not the same in all hospitals. In a recent study from a peripheral district general hospital the mortality was $15 \%,{ }^{9}$ whereas in teaching hospitals it is often substantially 